\title{
Más allá de las cualidades: una aproximación al sentimiento amoroso desde el lenguaje poético
}

\author{
Beyond qualities: an approach to the sentiment of love \\ from the poetic language
}

Sebastián Pereira Restrepo

Universidad del Rosario, sebastian.pereira@urosario.edu.co,

ORCID: 0000-0002-1924-3032

Date of reception:

28/09/2020

Date of acceptance: 29/07/2020

Citation: Pereira Restrepo, Sebastián, "Más allá de las cualidades: una aproximación al sentimiento amoroso desde el lenguaje poético", Revista Letral, n. ${ }^{\circ}$ 24, 2020, pp. 262280. ISSN 1989-3302.

DOI:

http://dx.doi.org/10.30827/R L.voi24.11180

Funding data: The publication of this article has not received any public or private finance.

License: This content is under a Creative Commons Attribution-NonCommercial 3.0 Unported license.

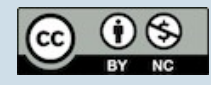

\begin{abstract}
RESUMEN
Se expone la idea de que las cualidades valiosas de la persona amada son el fundamento del sentimiento amoroso ("teoría de las cualidades"). Se señala en qué medida esta idea permitiría explicar ciertos rasgos centrales del sentimiento amoroso: sus aspectos racionales e irracionales, su orientación al descubrimiento de la belleza y la excelencia de la persona amada, así como su tendencia a singularizarla y distinguirla entre todas las demás personas. Se presentan algunas objeciones a la teoría de las cualidades, especialmente en relación con su concepción de las personas como agregados de cualidades. Se sugiere restringir la teoría de las cualidades, pero conservando la idea de que el sentimiento amoroso permite una percepción del valor y la belleza de la persona amada. Se muestra que el lenguaje de las cualidades es un "juego del lenguaje" inadecuado al sentimiento amoroso. Finalmente, a través de un ejemplo de la poesía de Pablo Neruda, se indica cómo el "lenguaje del amor" puede referirse al valor y la belleza de la persona amada sin recurrir al lenguaje de las cualidades.
\end{abstract}

Palabras clave: amor; teoría de las cualidades; valor de la persona amada; juego del lenguaje; poesía.

\begin{abstract}
The article begins by presenting the idea that the valuable qualities of the beloved person are the ground of the sentiment of love ("theory of qualities"). It is pointed out that this idea would allow to explain certain central features of the sentiment of love, namely some of its rational and irrational aspects, its orientation towards the discovery of the beauty and excellence of the beloved person as well as its tendency to singularize and distinguish the beloved one from among every other person. Some objections against the theory of qualities are exposed, particularly those related with its conception of persons as aggregates of qualities. It is proposed that the theory of qualities should be restricted but maintaining the idea that the sentiment of love allows a perception of the value and beauty of the beloved person. It is showed that the language of qualities is a "language game" inadequate to the sentiment of love. Finally, through an example of Pablo Neruda's poetry it is indicated how the "language of love" can refer to the value and the beauty of the beloved person without recurring to the language of qualities.
\end{abstract}

Keywords: love; theory of qualities; value of the beloved person; language game; poetry. 


\section{La teoría de las cualidades}

De acuerdo con una posible lectura de El Banquete, es nada menos que Platón -en la voz de Diotima- quien inauguró lo que de ahora en adelante llamaremos la teoría de las cualidades en relación con el amor. Así, en El Banquete Platón caracteriza el amor, en sus niveles más elevados, como la aspiración a la cualidad de lo absolutamente bello, de "la belleza en sí" (211d). Según esa idea, lo bello es el objeto mismo, o si se quiere, la base o el fundamento del eros. Si restamos a la formulación platónica el adjetivo "absoluto" y añadimos en lugar de "la belleza en sí" una pluralidad de cualidades que de alguna percibimos como excelentes, obtenemos una concepción más bien prosaica de aquello que en realidad amamos cuando amamos a alguien: anhelamos un conjunto de cualidades que percibimos como excelentes, nos atraen y despiertan en nosotros el sentimiento amoroso.

En uno de los aforismos que componen sus Pensamientos, Pascal formula con claridad la anterior idea, ampliándola en varias direcciones:

Y si se me ama por mi juicio, por mi memoria, ¿̇se me ama a
mí? No, pues yo puedo perder estas cualidades sin perder mi
yo. ¿Dónde está, pues, ese yo, si no reside ni en el cuerpo ni en
el alma?, ¿y cómo amar el cuerpo o el alma, sino por estas cua-
lidades, que no son lo que hace al yo, puesto que son perece-
deras? Porque ¿se amaría la sustancia del alma de una persona
abstractamente, cualesquiera fuesen las cualidades que tu-
viera? Esto no puede ser, y sería injusto. No se ama, pues, ja-
más a nadie, sino solamente a las cualidades (213).

No amamos un yo puro, imperecedero, que se encuentre más allá de las cualidades. Semejante objeto del amor no sólo es imposible -"Esto no puede ser"-, sino además "injusto": amar de esa manera significaría ser indiferente a las cualidades de la persona amada, con lo cual el sentimiento amoroso no sería más que un movimiento del alma del todo arbitrario e irracional. Pues si la sustancia del alma, al estar desprovista de cualidades, es la misma en cada ser humano, ¿no resultaría acaso completamente arbitrario el que yo me incline amorosamente hacia esta o hacia aquella persona? Para Pascal es claro que el amor debe fundamentarse en cualidades si queremos salvarlo de la acusación de una perfecta irracionalidad. Esto significa, sin embargo, que el amor está sujeto a la transitoriedad de las cualidades, que son "perecederas", como escribe Pascal. Además, hemos de conformarnos con que, en estricto sentido, no es posible amar a alguien, sino tan sólo a sus cualidades. Cuando alguien dice sinceramente amarnos, en realidad está diciendo que ama tales y cuales cualidades nuestras. En relación con el objeto del amor, nuestro lenguaje nos induce sistemáticamente a error. O quizás, como 
pareciera sugerirlo Pascal, la idea de un yo inmutable, más allá de las cualidades, es una quimera filosófica y el yo no es nada más que un cúmulo de cualidades. En tal caso, amar a alguien efectivamente no es otra cosa que amar un determinado conjunto de cualidades.

En cuanto a la percepción de las cualidades del ser amado, el teórico de las cualidades afirmará que es perfectamente posible errar en ello e inventar cualidades y excelencias y proyectarlas donde no las hay. Podemos creer equivocada y sistemáticamente que una determinada persona posee un conjunto de cualidades irresistibles para nosotros y de las cuales nos enamoramos. La observación de que en el amor con frecuencia inventamos y proyectamos cualidades es el punto de partida de la famosa teoría de la "cristalización", expuesta por Stendhal en Del amor. Según Stendhal, la persona real tan sólo proporciona el material bruto que, mediante una operación constante de la mente del que ama, es transformado en excelencias y "perfecciones" que en realidad no existen, pero que quienes aman toman por reales y que son justamente el fundamento de su amor. El proceso mediante el cual la mente de quien ama fabrica una imagen irreal del ser amado, es lo que Stendhal llama "cristalización":

Si se deja a la cabeza de un amante trabajar durante veinticuatro horas, resultará lo siguiente:

En las minas de sal de Salzburgo, se arroja a las profundidades abandonadas de la mina una rama de árbol despojada de sus hojas por el invierno; si se saca al cabo de dos o tres meses, está cubierta de cristales brillantes; las ramillas más diminutas, no más gruesas que la pata de un pajarillo, aparecen guarnecidas de infinitos diamantes, trémulos y deslumbradores; imposible reconocer la rama primitiva.

Lo que yo llamo cristalización es la operación del espíritu que en todo suceso y en toda circunstancia descubre nuevas perfecciones del objeto amado (98).

Pese a que en este pasaje Stendhal habla de "descubrir" en lugar de "inventar", a lo largo de su tratado queda claro que las supuestas "perfecciones" del ser amado no son otra cosa que invenciones de quienes aman. Así, en uno de muchos pasajes semejantes de Del amor, Stendhal escribe lo siguiente acerca del funcionamiento de la mente de quienes aman: "ven esas cosas no como son, sino como ellos las han creado, y gozando la apariencia imaginada de esas cosas creen gozar de la cosa misma" (134). Anticipando a Freud, Stendhal identifica en el deseo el mecanismo responsable de la cristalización: "Este fenómeno que yo me permito llamar cristalización viene de la naturaleza que nos ordena el placer [...] del sentimiento de que los placeres aumentan con las perfecciones del ser amado y de la idea de que este me pertenece" (99). En todo caso, si bien aquí se trata de cualidades 
siempre fantaseadas por una mente dominada por el "principio del placer", la teoría de la cristalización es también una teoría de las cualidades, pues asume que el amor se fundamenta en las "perfecciones" del ser amado.

Asimismo, las cualidades que constituyen el fundamento del sentimiento amoroso pueden ser relevantes para la identidad de la persona amada -como podría ser, por ejemplo, el caso de la generosidad-, o pueden ser cualidades que tendemos a considerar como superficiales, como por ejemplo el color del pelo. Este último caso es el que describe William Butler Yeats en uno de sus poemas:

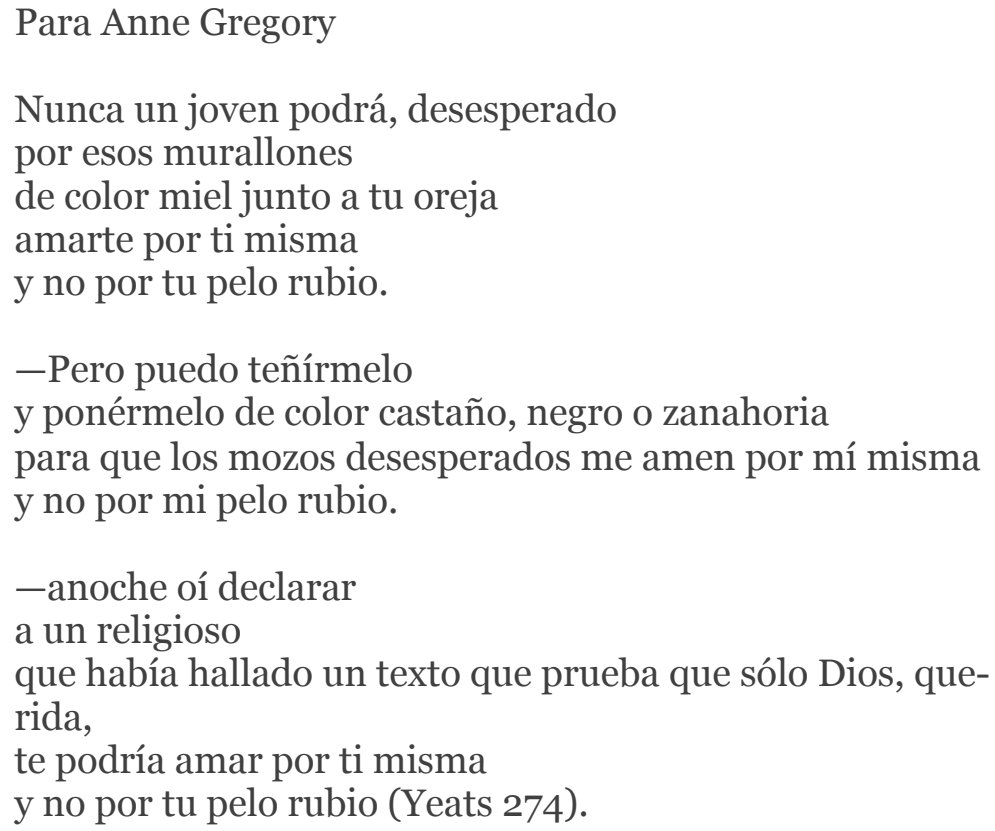

Aquí no se trata, por lo menos desde la perspectiva de Anne Gregory, de una cualidad relevante para su identidad, y sin embargo parece constituir, según las palabras del "religioso", el fundamento del amor que pueda sentir cualquier joven hacia ella. Tan pronto como Anne cambie su pelo rubio por un color menos llamativo, los "mozos desesperados" dejarán de amarla, tal parece ser la idea expresada por el religioso, quien en el poema figuraría como defensor de la teoría de las cualidades: según él, sólo el buen Dios es capaz de amarnos por nosotros mismos.

Sin embargo, independientemente de que las cualidades correspondan a aspectos relevantes o irrelevantes de la persona, y de que efectivamente sean cualidades de la persona (y no meras fantasías e invenciones del que ama), e independientemente de si las cualidades son la base de un amor superficial y efímero, o de un amor permanente y profundo, son en todo caso cualidades hacia las que se dirige y en las cuales se fundamenta el sentimiento amoroso, tal es la idea de la teoría de las cualidades. Hay 
amores de amores, pero común a todos ellos es el hecho de que se dirigen a estas o a aquellas cualidades.

Como toda teoría, la teoría de las cualidades parte de algunos supuestos, que en este caso corresponden a algunas de las características fundamentales que solemos atribuir al amor, y busca explicar a partir de allí otras características consideradas también como constitutivas del sentimiento amoroso. Algunos de los presupuestos centrales de los cuales parte la teoría de las cualidades, así como las características que estaría en capacidad de explicar, o al menos de incorporar, son los siguientes:

a. Racionalidad. Pese a que muchos sostengan lo contrario, para el teórico de las cualidades el sentimiento amoroso no es irracional, puesto que se rige por una racionalidad mínima. El amor cumple con una condición mínima de racionalidad en el sentido de que se basa o se fundamenta en algo en lugar de en nada. ¿Qué más natural que decir que amamos a alguien por...y a continuación nos refiramos a algunas de las cualidades en las que se fundamenta nuestro amor?, señala el teórico de las cualidades. Las cualidades de la persona amada figurarían, entonces, como razones del amor, en la medida en que dan cuenta del origen, de la permanencia y del final del sentimiento amoroso ${ }^{1}$.

b. Belleza. El amor no sólo es racional en el sentido mínimo de que se fundamenta en algo, a saber, en las cualidades del ser amado. Las cualidades en que se basa el amor son, además, esencialmente las cualidades valiosas de la persona amada. Ahora bien, quizás el término más apropiado para designar esa constelación de excelencias y "perfecciones" que despiertan el sentimiento amoroso y lo alimentan a cada momento sea el de la belleza. Así, el teórico de las cualidades puede afirmar, siguiendo una tradición que se remonta a Platón, que el amor se basa en una percepción de la belleza del ser amado.

Pero, además, al amor suele atribuírsele el poder de abrirnos los ojos a la belleza de la persona amada. Para Platón, el amor es precisamente una forma elevada de conocimiento de la belleza. Esto quiere decir que la belleza del ser amado no se encuentra ahí simplemente, a la vista de todo el mundo. La idea es, más bien, que el amor es la capacidad que tiene el alma de transformar la mirada de tal manera que quien ama puede percibir la

${ }^{1}$ Estas razones en que se fundamentaría el amor difieren de las razones que brinda el amor como una fuente de razones para actuar para y por la persona amada. En su obra Las razones del amor, el filósofo Harry Frankfurt ha desarrollado ampliamente la idea del amor como fuente de razones. La temática acerca de las razones del amor, tanto en el sentido que Frankfurt le da a esta expresión como en el que empleo a lo largo de este artículo, ha sido explorado en tiempos recientes por la filosofía analítica, p. ej. en los trabajos de Helm (2010), Jollimore (2011) y Velleman (1999). 
belleza del ser amado en toda su magnitud, en todo su resplandor. La belleza así descubierta es una belleza completamente real que sin embargo no es visible para todo el mundo, al menos no como lo es para quien ama.

"Belleza" no ha de entenderse aquí de forma restrictiva, en términos de "belleza física", sino mucho más ampliamente, como símbolo de la especial configuración de aquello que percibimos como esencialmente valioso y excelente en la persona amada. Para quien ama, esa excelencia se transluce también en la corporalidad de la persona amada, de manera que su belleza nunca será sólo física: a los ojos del que ama, la corporalidad y gestualidad de la persona amada, su "físico" siempre trasciende la belleza meramente exterior, pues es ante todo expresión de una humanidad excelente y única. O como escribe Ortega y Gasset en sus Estudios sobre el amor: "Amar es algo más grave y significativo que entusiasmarse con las líneas de una cara y el color de una mejilla; es decidirse por un cierto tipo de humanidad que simbólicamente va anunciado en los detalles del rostro, de la voz y del gesto" (141).

Al tenor de la anterior idea, no es pese al amor que el amante ve con mayor claridad a la persona amada, sino todo lo contrario: es gracias al amor que quien ama está en capacidad de abrir sus ojos a la otra persona, a su particular belleza humana. En su versión más radical, esta concepción sostiene que sólo a través del amor somos capaces de descubrirnos como realmente somos. Ello significaría, a la inversa, que quienes no aman sólo tienen una visión difusa de los no amados por ellos.

c. Selectividad. "Encuentro en mi vida millones de cuerpos; de esos millones puedo desear centenares; pero, de esos centenares, no amo sino uno" (Barthes, Fragmentos 27). ¿Cómo se explica que, de entre el vasto número de personas que conocemos a lo largo de la vida, sólo unas pocas despierten en nosotros el sentimiento amoroso? Responder esta pregunta significa dar una explicación a uno de los grandes misterios del amor, a saber, el referente a su selectividad. En el vocabulario que hemos estado empleando, la selectividad del amor puede plantearse así: las razones del amor no son generalizables, "no existe ninguna cualidad que enamore universalmente", como escribe Ortega y Gasset (104). No hay - por fortuna- un único tipo de belleza humana a la cual seamos susceptibles todas las personas. ¿Qué es lo que hace, pues, que el amor nos abra los ojos a la belleza de sólo unas pocas personas en el transcurso de la vida?

Desde el punto de vista de una teoría de las cualidades podría intentarse la siguiente respuesta. Cada uno de nosotros posee una perspectiva valorativa única, o, para ser más específicos: cada uno de nosotros encarna una perspectiva única sobre la belleza humana. Dicha perspectiva limita la belleza que podemos 
percibir en cada caso: "nuestra visión de los valores, al igual que nuestra visión del universo, no nos dejan ver en cada caso más que un sector del mundo [...] lo que hace que nos encontremos, por tanto, vinculados a la perspectiva" (Frankl 71-72).Viktor Frankl plantea esta idea para señalar de qué manera lo que cada uno de nosotros debe hacer con su vida está condicionado en cada caso por los valores que podemos percibir desde una determinada perspectiva, que siempre es única. Sin embargo, la idea es perfectamente trasladable a la esfera del amor: a quién podemos amar está condicionado por la perspectiva, única e irrepetible, que cada uno de nosotros tiene sobre lo humanamente bello. En la formación de dicha perspectiva intervienen, por lo demás, los mismos elementos culturales, biográficos y biológicos encargados de moldear nuestro carácter de manera única a lo largo de la vida.

d. Unicidad. El amor singulariza a la persona amada, destacándola de entre todas las demás y haciendo que quien ama la perciba como única e irremplazable. El sentimiento amoroso contrasta aquí marcadamente, por ejemplo, con el deseo sexual, capaz de excitarse ante una pluralidad de posibles "objetos del deseo". El carácter único que adquiere el ser amado a los ojos de quien ama es la contraparte objetiva del fenómeno subjetivo de la selectividad. Si la selectividad del sentimiento amoroso significa que poseo una perspectiva singular sobre lo humanamente bello, la unicidad del ser amado designa esa determinada persona -el ser amado-, cuya belleza puedo descubrir desde mi particular perspectiva.

Para el teórico de las cualidades, la unicidad del ser amado no es, sin embargo, un hecho absoluto. No debe interpretarse como si, por principio, ninguna otra persona pudiera reemplazar al ser amado. El que amemos a una determinada persona no debe interpretarse como si ello significara que la amemos "más allá de sus cualidades", "independientemente de sus cualidades", etc. Para el teórico de las cualidades esto tan sólo significa que esa persona "actualiza" o "ejemplifica" la belleza humana en una determinada forma para la cual somos receptivos dada nuestra particular perspectiva valorativa. Esto quiere decir, a su vez, que cada uno de nosotros posee un determinado rango o espectro de visión de la belleza humana. Para cada persona existe un determinado conjunto de cualidades a las cuales somos susceptibles, de manera que las personas cuya belleza cae dentro de ese rango, son objetos del amor potenciales.

e. Irracionalidad. La teoría de las cualidades esbozada hasta ahora brinda una reconstrucción del amor que destaca sus rasgos más racionales. La teoría de las cualidades daría, sin embargo, una imagen sesgada del amor si no integrara los aspectos 
irracionales de este fenómeno. Veamos brevemente algunos tipos de irracionalidad típica del amor y la manera como podrían comprenderse a partir de la teoría de las cualidades.

Es posible amar a alguien pese a que sabemos que esa persona, o la relación que tenemos con ella, posee cualidades predominantemente negativas. Ese escenario constituye por cierto un caso paradigmático de la irracionalidad del amor y de su faceta más desdichada: pese a que una parte de nosotros sabe de las consecuencias nefastas de ciertas cualidades de la otra persona o de su incompatibilidad con las nuestras, ese conocimiento no basta para alejarnos de esa persona, ni mucho menos para poner punto final al sentimiento amoroso. Aquí amor y conocimiento siguen sendas opuestas. En tal caso diremos quizás que nuestro amor es fallido. Pero sólo es posible hablar aquí de un amor o de una relación amorosa fallida, porque tenemos un concepto de las formas logradas del amor, de lo que solemos llamar "amor verdadero", en las cuales el amor se fundamenta en cualidades que son y que percibimos como valiosas.

Otra forma conspicua de irracionalidad en el amor tiene que ver con el fenómeno de la cristalización descrito por Stendhal, en el cual el ser amado no es la persona real, sino una construcción de la fantasía de quien ama. De modo semejante, también podría hablarse de una irracionalidad amorosa cuando quien ama no es en modo alguno consciente de las verdaderas razones del amor y sólo puede referir pseudo-razones. Estas otras dos formas de irracionalidad se explicarían, sin embargo, ante la posibilidad de percibir correctamente cualidades y excelencias, por contraposición a lo que ocurre en la cristalización, o de ser al menos parcialmente conscientes de las verdaderas razones del amor.

Llevadas al extremo, estas formas de irracionalidad pueden constituirse en patologías del amor: saber a ciencia cierta que la persona amada es, por ejemplo, moralmente repugnante y sin embargo seguir con ella, es una forma de akrasia o incontinencia, una fractura interna en el alma de quien ama, en la cual el sentimiento amoroso no se pliega al conocimiento correcto que el amante tiene del ser amado. Pretender amar a alguien, pero en lugar de esa persona amar a una imagen enteramente construida por la propia fantasía, es una forma de autoengaño, como también es un autoengaño brindar razones del amor que no corresponden en absoluto con las verdaderas razones en que este se fundamenta.

Lo anterior no quiere decir en modo alguno que esas formas de irracionalidad sean negativas sin más y por lo tanto no tengan cabida en las formas logradas del amor. ¿No implica amar verdaderamente a alguien amar también algunas de sus cualidades negativas? En la primera etapa del amor, que llamamos enamoramiento, ¿no es acaso indispensable ilusionarnos en alguna 
medida sobre las cualidades de la otra persona? ¿No hace parte de la bondad y benevolencia del amor el practicar, mediante la fantasía, algunos retoques a las cualidades del ser amado, o al menos interpretarlas de la mejor manera posible? Y si queremos dejar intacto el misterio del amor, ¿no necesitamos dejar en la sombra algunas de sus razones? ¿Quién desea iluminar todo el fondo del amor y tener ante sí el conjunto total de sus razones?

En resumen, la teoría de las cualidades afirma que no es necesario recurrir a un vocabulario distinto del referente a las cualidades para determinar el fundamento del sentimiento amoroso.

\section{Dos objeciones a la teoría de las cualidades}

Sin embargo, la teoría de las cualidades puede resultar decepcionante para algunos, no sólo porque desencanta el amor y proyecta una imagen demasiado racional de él, sino porque en últimas no puede hacer justicia a por lo menos dos de las características esenciales del amor que he mencionado anteriormente: el conocimiento que proporciona el amor y la unicidad del ser amado. Por más que el teórico de las cualidades se esfuerce en brindar una caracterización convincente de esos rasgos, falla en comprender ambos fenómenos, y con ello en últimas al amor mismo. Por un lado, es equivocado concebir a las personas como meros "paquetes de cualidades", que es lo que sugiere la explicación de la unicidad del ser amado por parte del teórico de las cualidades. Individuum est ineffabile: el carácter único e irrepetible del ser humano no es comprensible en términos de cualidades generales. La persona es un todo que no puede descomponerse y analizarse en un "listado" de cualidades.

Esto nos permite entroncar con la segunda objeción a la teoría de las cualidades: si el individuo no es conocible mediante conceptos generales (cualidades), y el amor es "conocimiento del individuo", como escribe, por ejemplo, Iris Murdoch (Murdoch 34), entonces el conocimiento del ser amado como individuo debe de ser de un tipo diferente al que tiene lugar en la simple captación de cualidades generales. En todo caso, el sentimiento amoroso apunta más allá de lo general, y se dirige al individuo como a una totalidad única, como lo expresa p. ej. Georg Simmel en su "Fragmento sobre el amor":

Pues el amor [...] es aquel sentimiento que está enlazado a su objeto más estrecha e incondicionalmente que cualquier otro sentimiento [...] Lo decisivo es el hecho de que ninguna instancia de tipo más general se desliza en medio. Cuando admiro a alguien, esto es mediado por la propiedad, en cierto modo general, de lo digno de ser admirado [...] Pero es propio del amor, cuando este ya ha surgido, excluir de su objeto la 
cualidad mediadora, siempre relativamente general, que, por ejemplo, ha hecho surgir el amor para su objeto. Está ahí como una intención orientada inmediata y centralmente a este objeto y muestra su esencia auténtica e incomparable precisamente en los casos en los que incluso sobrevive la eliminación inequívoca de la razón de su surgimiento (46-47, traducción modificada).

Si bien Simmel reconoce aquí que el amor tiene razones por las cuales surge -"la cualidad mediadora, siempre relativamente general"-, se refiere sin embargo al amor como a un sentimiento que, una vez que ha surgido, deja tras de sí las cualidades generales que inicialmente podrían haberlo motivado. Para Simmel, el momento determinante del amor consiste justamente en la referencia, la "intención" directa e inmediata del sentimiento amoroso a la persona amada.

La objeción que presento aquí a la teoría de las cualidades no se refiere, sin embargo, al amor de eros frente al amor de ágape, el amor cristiano, cuyo modelo es el amor de Dios a los seres humanos. El amor de Dios, el ágape, ciertamente no se fundamenta en modo alguno en las cualidades valiosas del ser humano. No es un amor "carencial", que anhele "completar" con las cualidades del ser amado aquello de lo cual carece y que por lo tanto desea. Es indiferente al valor o desvalor de nuestras cualidades y merecimientos. Se prodiga tanto al virtuoso como al pecador. El amor de Dios es, contrario al eros, creador de valor: no somos amados por Dios porque él anhele en nosotros estas o aquellas cualidades valiosas, es porque somos amados por Dios que adquirimos valor en primer lugar².

La razón por la cual considero que el ágape no constituye una verdadera alternativa a la teoría de las cualidades es la misma que he atribuido antes al "religioso" del poema de Yeats: sólo Dios es capaz de amarnos independientemente de nuestros aspectos valiosos. En el amor humano, y especialmente en el contexto del amor erótico o romántico, 3 que es el que nos ocupa aquí, el valor que percibimos en la otra persona sí que juega un papel determinante en el sentimiento amoroso.

La objeción se refiere, más bien, a la idea de que el amor se dirige a la persona amada entendida como un "paquete de cualidades", de las cuales podamos hacer una suerte de listado que agote las razones del amor. Ciertamente hay algo profundamente inadecuado e incómodo en esta idea. Sin embargo, rechazarla no implica en modo alguno asumir que el sentimiento amoroso sea

${ }^{2}$ Una exposición clásica del contraste entre el amor de eros y el de ágape se encuentra en la obra Eros y ágape, de Anders Nygren.

3 El amor de padres a hijos, por el contrario, se presta más a una interpretación desde la perspectiva del ágape. En Las razones del amor, el filósofo Harry Frankfurt desarrolla esa perspectiva. 
independiente del valor y la belleza percibidos en la otra persona, o lo que es aún más radical, que el amor no tenga fundamento alguno, como lo sostiene la posición irracionalista mencionada antes. Rechazar esa idea tampoco implica desechar sin más la teoría de las cualidades. En ese sentido, la propuesta que pienso desarrollar a continuación consiste más bien en restringir la teoría de las cualidades. Para ello, trataré de mostrar en qué medida el "juego del lenguaje" de las cualidades es hasta cierto punto inadecuado al lenguaje del amor, a los distintos juegos del lenguaje que lo componen.

\section{El "juego del lenguaje" de las cualidades y el len- guaje del amor}

Nuestro lenguaje puede verse como una vieja ciudad: una maraña de callejas y plazas, de viejas y nuevas casas, y de casas con anexos de diversos períodos; y esto rodeado de un conjunto de barrios nuevos con calles rectas y regulares y con casas uniformes.

L. Wittgenstein, Investigaciones filosóficas $§ 18$.

La idea de un "juego del lenguaje" fue formulada por Ludwig Wittgenstein, especialmente en sus Investigaciones filosóficas. Según Wittgenstein, es incorrecto pensar el lenguaje como si a cada palabra le correspondiera un significado fijo y único que residiera en una suerte de esfera ideal y fuera independiente del contexto práctico en que usamos las palabras. Por el contrario, el concepto de juego del lenguaje permite a Wittgenstein estudiar el lenguaje como un vasto y complicado entramado de prácticas -un sinfín de "juegos del lenguaje"-, cada una de las cuales está gobernada por reglas y se encuentra entretejida con actividades no lingüísticas. Los juegos del lenguaje son, entonces, actividades reglamentadas que encadenan palabras con acciones, con miras a una finalidad práctica: "Llamaré también 'juego del lenguaje’ al todo formado por el lenguaje y las acciones con las que está entretejido" (Wittgenstein §7). De este modo, el significado de las palabras viene a ser una función del uso que les damos dentro de un determinado contexto práctico, dentro de un juego del lenguaje.

Hablar del vocabulario referente a las cualidades en términos de un juego del lenguaje, o de un conjunto de tales juegos, implica, al tenor de lo anterior, pensarlas en relación con el uso y la finalidad que les damos dentro de determinados contextos prácticos. Esos contextos prácticos de uso -esos juegos del lenguaje- nos son familiares a todos, hacen parte de nuestra "forma de vida", por usar otra expresión empleada por Wittgenstein en relación con la idea de juegos del lenguaje 4 , y sin embargo no

4 "La expresión 'juego del lenguaje' debe poner de relieve aquí que hablar el lenguaje forma parte de una actividad o de una forma de vida” (§23). 
reflexionamos demasiado acerca de ellos. El Wittgenstein de las Investigaciones pretendía investigar el lenguaje más o menos de ese modo, es decir, visibilizando los distintos juegos del lenguaje para dar una "representación sinóptica" de ellos (§122).

De este modo, al afirmar que el lenguaje de las cualidades es hasta cierto punto inadecuado al lenguaje del amor, quiero decir que los usos que solemos hacer del vocabulario de los atributos y cualidades son en buena medida extraños y opuestos al contexto del sentimiento y la relación amorosa. Allí, el lenguaje -o lo que suele ser una experiencia más común en el amor: la ausencia, los límites, la inadecuación misma del lenguaje-tiene una finalidad y un uso bien distintos de los que tenemos en mente cuando usamos el vocabulario de las cualidades, incluso cuando empleamos este mismo vocabulario.

¿Cuáles son, pues, algunas de las características de los conceptos que empleamos cuando hablamos de "las cualidades de una persona"? ¿Cómo y para qué los usamos? ¿Qué función tienen en nuestras prácticas comunicativas cotidianas? Aunque de manera bastante fragmentaria, quiero señalar aquí algunos de los usos y las características de nuestro vocabulario referente a las cualidades en la medida que resultan relevantes para mi exposición.

a) Algunas cualidades - por ejemplo, aquellas que expresamos con las palabras "inteligente", "divertido", "con sentido del humor", "generoso"- denominan rasgos o disposiciones de carácter, mientras que otras se refieren a características del aspecto físico, tales como bajito, enjuto, atlético, grande, etc.

b) $\mathrm{Al}$ atribuir rasgos de carácter registramos regularidades en el comportamiento de otras personas que de alguna manera resultan relevantes para nosotros y nos llaman la atención. En ese sentido, las cualidades tienen un significado retrospectivo. Abrevian diversos tipos de experiencias que hemos acumulado con una persona. Pero también tienen un sentido prospectivo y predictivo en la medida en que expresan la expectativa de un determinado comportamiento bajo determinadas circunstancias. Si A nos pregunta cómo es B y respondemos describiendo las cualidades de B, nuestro interlocutor puede formarse, aunque sea vagamente, una imagen del comportamiento futuro de A en determinados sentidos relevantes.

c) El lenguaje de las cualidades abstrae de las situaciones concretas con base en las cuales determinamos esta o aquella cualidad y de la forma específica que adquieren las cualidades en una determinada persona. Al hablar de una cualidad -en el sentido de una disposición de carácter-, no se está diciendo nada de la situación con base en la cual establecemos esa cualidad en alguien. Tan sólo comunicamos que existe una regularidad respecto a algo. 
d) La descripción de alguien mediante cualidades es claramente inespecífica. Si alguien nos comunica que A es una persona "divertida", podemos asociar las cosas más diversas a esa cualidad: que ríe fácilmente, que cuenta bromas, que tiene historias interesantes para contar y por eso no nos aburriremos con ella, etc. Este carácter inespecífico de las cualidades con las cuales expresamos rasgos de carácter también aplica a las cualidades referentes a las características del aspecto físico de una persona. Decir, por ejemplo, que alguien es "atlético" nos da una idea de su complexión física, pero omite por completo especificar los detalles particulares en que consiste su atleticidad.

A partir de lo anterior es posible circunscribir los límites del lenguaje de las cualidades y sus posibles usos: el lenguaje de las cualidades nos permite, con una y la misma palabra, abarcar una gran cantidad de fenómenos y situaciones distintas. Como conceptos para disposiciones de carácter, las cualidades tienen la finalidad de orientarnos de manera rápida y práctica en nuestro trato e intercambio cotidiano con otras personas. Atribuir cualidades a una persona tiene, las más de las veces, la finalidad de delimitar un posible rango de interacción con ella en función de ciertas expectativas generales referentes a su comportamiento. No sólo son útiles para nuestra propia orientación, sino también para la de otras personas a quienes eventualmente comunicamos nuestros hallazgos.

El grado de generalidad y abstracción de las cualidades las hace una herramienta de orientación indispensable en el ámbito de las relaciones impersonales, en las que en buena medida la persona no interesa en cuanto individuo, sino más como un agregado de funciones. En ese sentido, la esfera del trabajo constituye por ejemplo un escenario paradigmático del uso típico del lenguaje de las cualidades y su función social. Piénsese en el texto de un posible anuncio de empleo: "Se busca persona entusiasta y extrovertida, seria y responsable, comprometida, rigurosa, con espíritu de equipo...". Aquí efectivamente basta con que las cualidades de la persona "encajen" en forma general con lo que ha dado en llamarse el "perfil laboral", que no es otra cosa que un listado de cualidades que han de habilitar a una persona para desempeñar un trabajo. Esto quiere decir que, en el ámbito de las relaciones impersonales -por ejemplo, en la esfera del trabajo-, la persona no es en modo alguno "única e irremplazable", como lo pretende el sentimiento amoroso 5 . Aplicado al trabajo, el dicho

5 El interés sociológico en el fenómeno del amor, del que Simmel nos brinda un ejemplo, se entiende en parte justamente a partir del carácter individualizante del amor a diferencia de las relaciones impersonales que tienen lugar en la sociedad de masas propia del mundo moderno. El contraste entre relaciones impersonales y el amor como un medio de intensificar las relaciones 
de que "nadie es imprescindible", es del todo cierto y significa simplemente que, debido al grado de generalidad con que son requeridas ciertas funciones en la esfera laboral, muchas personas pueden ejemplificar las cualidades generales exigidas por un "perfil".

La irritación que se deriva de equiparar a la persona amada con un agregado de cualidades proviene en gran medida, creo yo, de que con ello se importa la lógica de las relaciones impersonales, que en últimas obedece a una lógica económica del cálculo y de la utilidad -entre más y mejores cualidades, mayor precio en el mercado laboral- al campo de las relaciones íntimas y personales. La concepción de la persona amada como una sumatoria de cualidades sugiere, en todo caso, que quien ama se comporta a la manera de un seleccionador de personal: la persona amada cumple provisionalmente los requisitos, pero otra persona con las mismas cualidades, o incluso otras mejores, también podría cumplirlos. La exclusividad del amor y su carácter individualizador ceden así a una lógica de la provisionalidad y del carácter remplazable de la persona amada. De igual manera, si el sentimiento amoroso está mediado sólo por un interés en lo general, difícilmente podría caracterizársele al tenor de Iris Murdoch como una atención a lo particular y un "conocimiento del individuo".

Sin embargo, esta interferencia de una lógica impersonal y utilitaria, representada en el lenguaje de las cualidades, con la lógica individualizante del sentimiento amoroso y su atención a lo particular, quizás no sea algo que venga de afuera del amor, sino que hasta cierto punto ha llegado a convertirse en interna al fenómeno amoroso mismo. A fin de cuentas, las páginas de contactos de parejas funcionan bajo la misma lógica de las bolsas de empleo. En unas y en otras se procura seleccionar a un candidato en función de determinadas cualidades. Según esa idea, el sentimiento amoroso no se encontraría en modo alguno en un estado "puro", sino que más bien, entremezclado con él, se hallan el interés pragmático, condensados, por ejemplo, en la idea de encontrar un "buen partido". Como sea, en el amor estas dos lógicas coexisten en una tensión. Y si la concepción de la persona amada como un cúmulo de cualidades resulta incómoda es porque al menos una parte del sentimiento amoroso se resiste a someterse a los dictados del interés y la utilidad.

Hasta ahora hemos visto los usos del lenguaje referente a las cualidades y las razones por las que estas se encontrarían en una tensión frente al sentimiento del amor. Falta explicitar cuáles son las limitaciones del lenguaje de las cualidades. Esto es fácilmente deducible a partir de la exposición anterior: el lenguaje

personales es precisamente uno de los puntos de partida de Niklas Luhmann en su Amor como pasión. 
de las cualidades no nos permite obtener ni expresar un conocimiento diferenciado de otra persona. Es propio de las cualidades brindar una caracterización compacta, pero gris y genérica, de las personas. Como expresión de un saber genérico referente a personas y situaciones, las cualidades expresan en realidad una cierta indiferencia frente a ellas: entre más impersonales sean nuestras relaciones, tanto más tendemos a pensar en la otra persona a través de un nebuloso esquema de cualidades y cuanto más nos distanciaremos de su realidad concreta. No obstante, hemos visto que el lenguaje de las cualidades es imprescindible dentro del ámbito de las relaciones impersonales que abundan en el mundo moderno.

Siguiendo la metáfora de Wittgenstein que sirve de epígrafe a esta sección y compara el lenguaje con una "una vieja ciudad", el lenguaje de las cualidades correspondería a las "calles rectas y regulares" en las que circulan a toda prisa las relaciones impersonales y muchas veces grises del mundo moderno. La "maraña de callejas y plazas" ofrece, en cambio, una imagen acertada del lenguaje del amor, más antiguo por su anclaje al sentimiento, de caminos sinuosos y apacibles recovecos donde quienes aman gustan de perderse y demorarse.

El lenguaje del amor se comporta en todo caso de manera bien distinta al lenguaje de las cualidades. Por "lenguaje del amor”, entiendo diversas prácticas: por ejemplo, las maneras como quienes aman cuentan sobre la persona amada y como la describen, bien sea para sí mismos, para otras personas o para la persona amada; las formas de pensar en la persona amada en cuanto ser amado, es decir, como objeto del sentimiento amoroso; las maneras de pensar y de referirse a uno mismo en cuanto que amante, y por supuesto también las maneras de interpelarse la pareja amorosa. Esas variedades del lenguaje del amor son ellas mismas prácticas del amor, y, además, se trata de prácticas centrales, pues si la forma de vida humana es indisociable del lenguaje, el amor también se articula y se configura de manera esencial en el habla.

Dentro de esa perspectiva del amor como fenómeno del lenguaje y del sentimiento amoroso como una percepción de valor y excelencia del ser amado, puede decirse que las cualidades comprenden un ámbito restringido de lo que quienes aman quieren decir, intentan decir y de hecho dicen en su "discurso amoroso"6. Las cualidades no son apropiadas para caracterizar a la persona amada en su humanidad singular, no pueden satisfacer el impulso hacia la individualización que es propio del sentimiento amoroso. Y, sin embargo, dado que la persona amada es

${ }^{6}$ Ese es el término que usa Roland Barthes en sus Fragmentos de un discurso amoroso y que en buena medida se corresponde con lo que, desde la filosofía del Wittgenstein tardío, llamo aquí los juegos del lenguaje del amor. 
percibida como valiosa, quien ama experimenta una tensión entre la necesidad de colmar a la persona amada con cualidades y al mismo tiempo alejarla, ponerla a salvo de ellas, como lo expresa Roland Barthes en sus Fragmentos de un discurso amoroso: "Industriosa, infatigable, la máquina de lenguaje que resuena en mí [...] fabrica su cadena de adjetivos: cubro al otro de adjetivos, desgrano sus cualidades, su qualitas" (230). Y escribe unas líneas más adelante: "Es preciso que el otro devenga a mis ojos puro de toda atribución [...] seré semejante al infans que se contenta con una palabra vacía para mostrar alguna cosa: Ta, Da, Tat (dice el sánscrito). Tal, dirá el enamorado: tú eres así, precisamente así” (231).

Ante esta inconmensurabilidad de la persona amada, el medio adecuado para hablar de ella consiste, por un lado, en contar historias en lugar de enumerar cualidades. Tan pronto como una persona nos importa en alguna medida, tenderemos hacia alguna forma de narración. Ello no significa en modo alguno prescindir del lenguaje de las cualidades, pero sí implica ponerlo al servicio de una perspectiva narrativa que dé cuenta de nuestras prácticas comunes, de las situaciones únicas que hemos vivido, en las que brilla lo que podríamos llamar con Walter Benjamin el "aura" de la otra persona, su ser irrepetible reflejado en su particular manera de ver y de abordar el mundo.

Por otro lado, el lenguaje poético es una forma excelsa de evocar a la persona amada en su valor inconmensurable, liberándola de las ataduras de un lenguaje genérico como es el lenguaje de las cualidades. En sus Cien sonetos de amor, Pablo Neruda llama la atención sobre esa intención del lenguaje poético desde la dedicatoria misma de los sonetos:

Tú y yo caminando por bosques y arenales, por lagos perdidos, por cenicientas latitudes, recogimos fragmentos de palo puro, de maderos sometidos al vaivén del agua y la intemperie. De tales suavizadísimos vestigios construí con hacha, cuchillo, cortaplumas, estas madererías de amor y edifiqué pequeñas casas de catorce tablas para que en ellas vivan tus ojos que adoro y canto. Así establecidas mis razones de amor te entrego esta centuria: sonetos de madera que sólo se levantaron porque tú les diste la vida (47).

Aquí, Neruda presenta sus sonetos como una morada construida exclusivamente "para que vivan tus ojos que adoro y canto", que simbolizan la expresión corpórea y más transparente de su ser interior. Asimismo, el "material" de esa morada poética proviene de los momentos transcurridos juntos, únicos e irrepetibles - "tú y yo caminando por bosques y arenales [...] recogimos fragmentos de palo puro"-, que sin embargo no se vierten aquí como historia y narración, sino que son destilados en su esencia poética. Al final de la dedicatoria, la palabra poética figura como 
un lenguaje exclusivo, que existe sólo para la persona amada, porque esta le ha dado vida en primer lugar.

El soneto que da inicio a la "centuria", es igualmente emblemático del deslinde del lenguaje poético respecto del lenguaje de las cualidades:

Matilde, nombre de planta o piedra o vino, de lo que nace de la tierra y dura, palabra en cuyo crecimiento amanece, en cuyo estío estalla la luz de los limones.

En ese nombre corren navíos de madera rodeados por enjambres de fuego azul marino, y esas letras son el agua de un río que desemboca en mi corazón calcinado.

Oh nombre descubierto bajo una enredadera como la puerta de un túnel desconocido que comunica con la fragancia del mundo!

Oh invádeme con tu boca abrasadora, indágame, si quieres, con tus ojos nocturnos, pero en tu nombre déjame navegar y dormir (48).

Este primer soneto es una evocación de la persona amada a partir de su nombre. Ahora bien, dentro del lenguaje, el nombre propio ocupa un lugar singular por cuanto es capaz de hacer referencia a un objeto independientemente de cualesquiera sean sus determinaciones particulares, sus cualidades. El nombre "Matilde" hace referencia a Matilde sin necesidad de referirse a ninguna de las características o cualidades de Matilde. En esta medida, el nombre propio contrasta con lo que en filosofía del lenguaje se denomina "descripciones definidas" del objeto, expresiones como la siguiente: "la mujer que conoció a Pablo Neruda en el Parque Forestal en 1946 y se casó con él en 1966”, que también designa a Matilde.

Tanto los nombres propios como las descripciones definidas se les conoce como "expresiones referenciales singulares". La función de esas expresiones es designar un único objeto. Sin embargo, mientras que la descripción definida se refiere a su objeto destacando una de sus determinaciones (cualidades), el nombre propio lo hace de forma directa, sin destacar esta o aquella cualidad suya. Así, el nombre propio mantiene una conexión íntima con su objeto, refiriéndose a él, pero dejándolo intacto en su totalidad7.

7 El contraste entre los nombres propios y las descripciones definidas es elaborado en la obra clásica de Saul Kripke El nombrar y la necesidad. 
El nombre propio es, por lo tanto, un elemento esencial del lenguaje del amor que se define justamente en oposición al lenguaje de las cualidades por cuanto permite a quien ama referirse a la persona amada sin descomponerla en sus determinaciones particulares. Justo de ese modo funciona el nombre de Matilde en este primer soneto, que articula una consciencia plena del poder evocador del nombre, capaz de llamar una totalidad sin reducirla a esta o a aquella cualidad. Así, el nombre "Matilde" figura en el soneto como "la puerta de un túnel desconocido que comunica con la fragancia del mundo". El nombre, como "puerta de un túnel", es un medio que conecta con la totalidad de la persona amada, totalidad simbolizada aquí como "la fragancia del mundo". La amada es un todo inabarcable, igual a un océano en el que "corren navíos de madera". Si el poema es un refugio de amor, el nombre de la persona amada cumple entonces la función de resguardarla en su totalidad como persona, poniéndola más allá de cualquier cualidad.

\section{Bibliografía}

Barthes, Roland. Fragmentos de un discurso amoroso. México, Siglo veintiuno editores, 1982.

Frankfurt, Harry. Las razones del amor. Barcelona, Paidós, 2004.

Frankl, Viktor. Psicoanálisis y existencialismo. México, FCE, 1978.

Helm, Bennett. Love, Friendship, and the Self: Intimacy, Identification and the Social Nature of Persons. Oxford, Oxford University Press, 2010.

Jollimore, Troy. Love's Vision. Princeton, NJ, Princeton University Press, 2011.

Kripke, Saul. El nombrar y la necesidad. México, UNAM, 2005.

Luhmann, Niklas. El amor como pasión: hacia una codificación de la intimidad. Barcelona, Ediciones Península, 1985.

Murdoch, Iris. "La idea de perfección”. La soberanía del bien, Iris Murdoch (ed.), Madrid, Caparrós Editores, 2001, pp. 11-49.

Neruda, Pablo. Antología poética. Córdoba, Ediciones del Sur, 2003. 
Nygren, Anders. Eros y ágape: La noción cristiana del amor y sus transformaciones. Barcelona, Sagitario, 1969.

Ortega y Gasset, José. Estudios sobre el amor. Madrid, Edaf, 1995 .

Pascal, Blaise. Pensamientos. Madrid, Alianza, 1981.

Platón. El Banquete, Fedón, Fedro. Barcelona, Labor, 1995.

Simmel, Georg. El individuo y la libertad: ensayos de crítica de la cultura. Barcelona, Ediciones península, 1986.

Stendhal. Del amor. Madrid, Alianza, 1968.

Velleman, J. David. “Love as a Moral Emotion”, Ethics, $\mathrm{n}^{0}$ 109, 1999, pp. 338-74.

Wittgenstein, Ludwig. Investigaciones filosóficas. Madrid, Altaya, 1999.

Yeats, William B. Poesía reunida. Valencia, Pre-Textos, 2010. 